\title{
PLANEJAMENTO E \\ PRÁTICA PEDAGÓGICA: \\ UM ESTUDO ENTRE DOCENTES DA REDE PÚBLICA MUNICIPAL DE ARARA-PB
}

\author{
PLANNING AND PEDAGOGICAL PRACTICE: A STUDY AMONG \\ TEACHERS OF THE MUNICIPAL PUBLIC NETWORK OF ARARA-PB \\ PLANIFICACIÓN Y PRÁCTICA PEDAGÓGICA: UN ESTUDIO ENTRE \\ DOCENTES DE LA RED PÚBLICA MUNICIPAL DE ARARA-PB
}

\author{
Andreia de Oliveira Santos da Costa* \\ (iD https://orcid.org/oooo-0oo2-2545-9403 \\ Ana Cláudia da Silva Rodrigues** \\ (iD https://orcid.org/oooo-0oo1-6621-1861
}

\begin{abstract}
REVISTA PEDAGÓGICA
Revista do Programa de Pós-graduação em Educação da Unochapecó | ISSN 1984-1566

Universidade Comunitária da Região de Chapecó | Chapecó-SC, Brasil

Como referenciar este artigo: COSTA, A. de O. S. da.; RODRIGUES, A. C. da. Planejamento e prática pedagógica: um estudo entre docentes da rede pública municipal de Arara-PB. Revista Pedagógica, Chapecó, v. 22, p. 1-24, 2020. DOI: http://dx.doi.org/10.22196/rp.v22io.4570
\end{abstract}

Resumo: Este artigo apresenta uma análise do planejamento e sua relevância como instrumento para a práticadocente.Oobjetivofoientender comoaorganização do planejamento contribui para que a ação educativa se materialize. A investigação aconteceu na cidade de Arara - PB - em cinco escolas públicas. Os sujeitos envolvidos foram trinta e cinco professoras que compõem o quadro de docentes das instituições pesquisadas, que lecionam na educação infantil e anos iniciais, além de quatro coordenadoras pedagógicas. A abordagem da pesquisa foi de cunho quantitativo e qualitativa. Os dados foram obtidos por meio de questionários e, depois de coletados e analisados, foi possível constatar que o planejamento direciona o sistema educacional e o trabalho no âmbito escolar; apresenta forte influência da ação pedagógica dos investigados e deve ser compreendido como uma ação inerente à instituição de ensino e ao trabalho do professor.

Palavras-chave: Planejamento escolar. Prática educativa. Trabalho docente.

Abstract: This article presents an analysis of planning and its relevance as an instrument for teaching practice. The main objective was to understand how planning organization contributes to the materialization of educational activity. The investigation took place in the city of Arara - PB - in five public schools. The subjects are thirty-five teachers who make up the teaching staff of the institutions that were researched who teach pre-school and elementary education, as well as four pedagogical supervisors. Regarding the research approach, it is quantitative. The data were obtained through questionnaires and, after being collated and analysed, it was possible to verify that planning drives the educational system and the work within the scope of the school; presents a huge influence on the pedagogical action on the people investigated and must be understood as being inherent within a teaching institution and within the work of a teacher.

Keywords: School planning. Educational practice. Teaching work.

Resumen: Este artículo presenta un análisis de la planificación y su relevancia como instrumento para la práctica docente. El objetivo fue entender cómo la organización del planeamiento contribuye para que la acción educativa se materializa. La investigación tuvo lugar en la ciudad de Arara - PB - en cinco escuelas públicas. Los sujetos involucrados fueron treinta y cinco profesoras que componen el cuadro de docentes de las instituciones investigadas, que enseñan en la educación infantil y años iniciales, además de cuatro coordinadoras pedagógicas. El enfoque de la investigación fue de cuño cuantitativo y cualitativo. Los datos fueron obtenidos por medio de cuestionarios $\mathrm{y}$, después de recolectados y analizados, fue posible constatar que la planificación dirige el sistema educativo y el trabajo en el ámbito escolar; es una fuerte influencia de la acción pedagógica de los investigados y debe ser entendida como una acción inherente a la institución de enseñanza y al trabajo del profesor.

Palabras clave: Planificación escolar. Práctica educativa. Trabajo docente. 


\section{Introdução}

Apresentamos, no decorrer deste texto, um estudo sobre o planejamento escolar, que deve ser compreendido como necessário no processo educacional. Vasconcellos (2002, p. 11) define o ato de planejar como "uma atividade que faz parte do ser humano, muito antes do que imaginamos. Nas coisas mínimas do dia a dia, como tomar um banho ou dar um telefonema, estão presentes atos de planejamento".

Esse é um processo que requer organização e se define como um instrumento orientador de toda ação do sujeito. Nas unidades escolares, $\mathrm{o}$ ato de planejar tem grande relevância, porque consiste em organizar o sistema de ensino da própria instituição, prever metas e sistematizar o trabalho a ser desenvolvido.

O planejamento se configura como um instrumento que gerencia e direciona um trabalho articulado e equilibrado. É um norteador para a escola e para os afazeres do professor. Ao considerar essas definições, objetivamos analisar como o planejamento contribui para que a ação educativa se materialize. Para isso, elencamos os seguintes objetivos específicos: investigar se o planejamento exerce influência no desenvolvimento da ação pedagógica; averiguar se os professores planejam previamente suas ações e como isso acontece; e verificar como os docentes fazem seu planejamento e que tipo de ajuda ele proporciona ao ser inserido na prática.

Neste artigo, trazemos uma discussão sobre os tipos e os níveis de planejamento que são essenciais para a educação. Com as informações apresentadas, esperamos cooperar com os estudos acadêmicos e explanar o assunto planejamento, de maneira que possa colaborar para o esclarecimento de possíveis dúvidas. Nesse contexto, tentamos responder ao seguinte questionamento: Como o planejamento contribui, como ferramenta, para materializar a ação educativa?

Quanto às discussões e às análises dos resultados apresentados neste estudo, foram baseadas nos pressupostos teóricos de autores como Castro, Tucunduva e Arns (2008), Cervi (2008), Gomes (2011), Libâneo (2013), Luckesi (2005), Menegolla e Sant'Anna (1999), Vasconcellos (2002), Zabala (1998) e Orso (2015).

\section{O planejamento como direcionador da prática pedagógica}

A educação ao longo dos tempos foi se constituindo como uma ação que não significa apenas a transmissão de informações, é vista como responsável pela formação do

\footnotetext{
* Licenciada em Pedagogia - Universidade Federal da Paraíba. Professora no Colégio Giordano - São Paulo.

E-mail: dreinha1o@hotmail.com

** Doutora em Educação pela Universidade Federal da Paraíba. Professora do magistério superior vinculada ao Programa de Pós-graduação em Educação, Universidade Federal da Paraíba.

E-mail: anaclaudia@ce.ufpb.br
} 
sujeito como um todo, uma fonte de transformação que inova e que influencia o desenvolvimento do indivíduo e do país. A escola tem a responsabilidade de oferecer aos alunos uma formação que os contemple em seus diferentes aspectos. Para atender às expectativas, precisa-se de uma proposta muito bem articulada, que se materializará através do planejamento.

Esse recurso, ao chegar às instituições, irá se caracterizar como algo organizacional, uma importante tarefa na administração da unidade educativa e um norteador para prosseguir com a parte administrativa e com a pedagógica. Configura-se como encadeamento de ações pensadas de maneira prévia a serem desenvolvidas em um momento futuro, uma antecipação consciente de etapas do trabalho previsto para acontecer. Portanto, é um recurso relevante para o bom funcionamento da educação. Vasconcellos (2002, p. 42) afirma que

o planejamento é uma mediação teórico-metodológica para a ação consciente e intencional. Tem por finalidade procurar fazer algo vir à tona, fazer acontecer, concretizar, e para isso é necessário 'amarrar', 'condicionar', estabelecer as condições - objetivas e subjetivas - prevendo o desenvolvimento da ação no tempo (o que vem primeiro, o que vem em seguida), no espaço (onde vai ser feita), as condições materiais (equipamentos que serão necessários), bem como a disposição interior, para que aconteça; caso contrário, vai-se improvisando, agindo sob pressão, administrando por crise.

Na concepção do autor, o planejamento é um instrumento que guia conscientemente a ação educativa, para que ela tenha suas intencionalidades e se evite uma rotina viciada e a improvisação. Planejar é ter um olhar minucioso, ao prever, passo a passo, um trabalho a ser realizado, para que se possa pensar nos recursos a serem utilizados, no tempo que será necessário e na sistematização das ações. Estabelecer os objetivos é relevante, porque eles agem como uma espécie de impulso, e isso implica a busca de resultados satisfatórios, que dão sentido à prática e melhoram sua qualidade.

Quando não se planeja, corre-se o risco de se perder no espontaneísmo, seja no campo de ensino ou em outros espaços de atuação social e profissional. Sem o planejamento nossas ações acontecem de maneira avulsa e sem intencionalidade, por isso com menos possibilidades de darem certo. Ao discutir educação, essa premeditação é indispensável. 
Orso (2015) discute a importância do planejamento, principalmente em tempos de precarização da educação. Para o autor,

Numa sociedade em que o conhecimento também deixou de ser espontâneo e passou a ser uma necessidade social deliberada, não é mais possível fazer educação sem um planejamento detalhado e rigoroso dos passos a serem dados, das ações a serem realizadas, dos objetivos visados, das variáveis que interferem no processo, das estratégias a serem adotadas, considerando a sociedade que se tem e a que se quer construir. A vida social atual, com sua complexidade, requer planejamento. É através dele que o homem organiza e disciplina sua ação, sua vida e a sociedade (ORSO, 2015, p. 226).

O planejamento dentro da esfera educacional irá se configurar em um processo por meio do qual há o estudo de ações e organização delas. A ideia de planejamento se baseia naquilo que pensamos, o registro escrito será o plano, onde se tem a sistematização do que foi pensado. No plano teremos a descrição do passo a passo a seguir, o que vale tanto para a escola como para os profissionais que fazem educação. Nesse esquema se planeja e se elabora o plano da escola, que Luckesi (2005, p. 112) irá definir como

- um conjunto de ações coordenadas entre si, que concorrem para a obtenção de certo resultado desejado;

- um processo que consiste em preparar um conjunto de decisões tendo em vista agir, posteriormente, para atingir determinados objetivos;

- é uma tomada de decisões, dentre possíveis alternativas, visando atingir os resultados previstos de forma mais eficiente e econômica.

Corroborando com Luckesi (2005) entendemos o planejamento como um agrupamento de ações ordenadas que vislumbra superar expectativas e atender ao que foi designado nos objetivos. É a previsão e a projeção de um trabalho a ser desenvolvido. Caracteriza-se como atemporal, visto que busca antecipar em tempo ainda não vivido, prever ações e situações cotidianas complexas e construir novas temporalidades. Essas temporalidades se materializam em dois momentos articulados: o da elaboração e o da operacionalização. A elaboração requer tempo para criação, análises de possibilidades, maturação das possíveis implicações dos atos planejados e racionalização buscando antever os resultados. Já a operacionalização envolve 
atuação. O planejamento elaborado, materializado através do plano, projetado, encontra o tempo futuro, os sujeitos com suas singularidades, em espaços de vida concretos, em ações cotidianas desenvolvidas na instituição que é imbricada de intencionalidades: a escola.

Por isso, planejar a educação escolar envolve não só os sujeitos que vivenciam cotidianamente a escola, mas toda uma rede política que se articula para pensar e planejar as ações educativas. Essa rede é responsável por elaborar o planejamento educacional, o planejamento escolar, o plano de ensino e o plano de aula. Cada planejamento é elaborado por sujeitos em níveis hierárquicos distintos que articulam as políticas educacionais e a materializam através da elaboração de planos com objetivos e metas a serem atingidas nos diversos espaços educativos.

$\mathrm{O}$ planejamento educacional corresponde à sistematização da educação de um modo geral, feito em nível nacional, estadual ou municipal. É o mais abrangente dos planejamentos e está ligado às políticas educacionais que surgem por meio das medidas do governo que estabelecem metas, traçam planos para a educação e se interligam ao desenvolvimento do país. É uma organização plena, que direciona todo o processo educacional, prevê e estrutura o sistema educativo. Conforme assevera Menegolla e Sant'Anna (1999, p. 41),

O planejamento deve atender a problemática a nível nacional, regional, comunitário escolar. Esse é o seu grande objetivo. Deve agir diretamente sobre a pessoa, a fim de atender às exigências e atingir as grandes metas educacionais. Há a necessidade de um planejamento nacional e de um planejamento regional; e da íntima relação desses planos são estruturados os planos curriculares das escolas que, por sua vez, dão as bases para a elaboração dos planos de ensino.

Portanto, o planejamento educacional é uma construção atrelada à responsabilidade de instâncias maiores. Parte das bases políticas e ideológicas do governo eleito e é ligado ao desenvolvimento socioeconômico do país. É uma sistematização de metas que são designadas para as unidades educativas e que dão subsídios para a elaboração dos demais planejamentos.

O planejamento escolar se subdivide em três planos: o da escola, o de ensino e o de aula. Ao discutir sobre esses níveis de planejamento, Menegolla e Sant'Anna (1999, p. 31) referem que "o planejamento, em sua relação aos diversos níveis, deve ser o instrumento direcional de todo o processo educacional, pois tem condições de estabelecer e 
determinar todos os recursos e meios necessários para a construção das metas da educação".

Nesse sentido, o planejamento direciona o processo educacional e se agrupa a uma linha de raciocínio baseada em metas a serem alcançadas. Isso significa pensar sobre como se pretende desenvolver a educação.

Segundo Libâneo (2013, p. 253),

O plano da escola é o plano pedagógico e administrativo da unidade escolar, onde se explicita a concepção pedagógica do corpo docente, as bases teórico-metodológicas da organização didática, a contextualização social, econômica, política e cultural da escola, a caracterização da clientela escolar, os objetivos educacionais gerais, a estrutura curricular, diretrizes metodológicas gerais, o sistema de avaliação do plano, a estrutura organizacional e administrativa.

Esse plano compreende a dinâmica de organização institucional da unidade de ensino e congrega informações sobre as características particulares da instituição e a realidade social, cultural e econômica do local onde está inserida. É elaborado para orientar os trabalhos durante o ano letivo, o que se espera desenvolver no ensino e determinar, em linhas gerais, os objetivos que a escola almeja alcançar. Tem por base as orientações curriculares nacionais, as perspectivas de formação de sujeitos, as concepções de escola e qual sociedade se quer construir. Projeta um futuro a partir do presente, da realidade local, nacional e internacional.

Em relação ao plano de ensino, cada professor, a partir dos direcionamentos nacionais, estaduais e ou municipais e da escola, estabelece seu trabalho ao longo do ano. A elaboração do plano de ensino é exclusiva do docente, por isso requer uma atenção especial. Para Oliveira (2011, p. 123),

O plano de ensino consiste na previsão do trabalho docente e discente na construção do conhecimento durante um período letivo. Ele visa a organizar o ensino e a aprendizagem de modo a promover o bom desempenho do aluno e do professor na execução do conteúdo disciplinar. Ele pode ser elaborado distribuindo o conteúdo disciplinar ao longo do semestre ou do ano letivo, conforme a organização institucional. De igual modo, o conteúdo pode ser distribuído por unidades, fazendo, assim, um plano de atividades a serem executadas nos diversos momentos ao longo do ano ou do semestre letivo. 
Oliveira (2011) nos ajuda a entender que esse plano se configura como um roteiro por meio do qual se organizam as disciplinas, os conteúdos são distribuídos por unidades e sugestões de momento para as atividades serem realizadas. Para complementar, é interessante fazer uma ponte com Libâneo (2013), que apresenta um modelo para elaborar um plano de ensino e sugere os seguintes elementos: Nome da disciplina, série, ano, quantidade de aulas, justificativa da disciplina, objetivos gerais e específicos, conteúdos, metodologias e bibliografias. Um plano bem organizado facilita a vida do professor, durante o ano ou o semestre, e servirá como referência para elaborar os planos de aula diários.

Porém, destacamos que não se trata do preenchimento de formulário no início do ano apenas, uma prática quase sempre vazia de cunho pedagógico; não se resume a mais uma atividade burocrática cumprida, que depois será esquecida. Esta atividade de planejar o ensino se reveste de dimensões transcendentes, visto que não se baseia somente na seleção e organização do que deverá ser ensinado. Planejar o ensino é mais do que a organização epistemológica e metodológica dos saberes a serem mediados; é, antes de tudo, o ato de estabelecer os caminhos que trilharão os alunos, de colaborar com a constituição de suas identidades, de projetar parte de suas vidas.

O plano de aula é o registro do que se almeja alcançar, a descrição do passo a passo sobre como prosseguir a aula. É muito particular e deve ser vinculado à proposta dos planos anteriores. Sua utilização dá mais segurança ao professor, e quando bem elaborado, significa que houve uma preocupação em pensar na aula. A intenção desse roteiro é de buscar excelência quando estamos no momento da prática. Takahashi e Fernandes (2004, p. 116) afirmam que "os professores, ao utilizarem o plano de aula, poderão ter maior confiança e dominar a situação a ser desenvolvida, pois o seu saber estará embasado na teoria e na prática”.

Gomes (2011, p. 4) ressalta

O planejamento de sala de aula desemboca na prática do professor e do aluno; por isso exige muito compromisso associado a algumas limitações e possibilidades. O que acontece em muitas instituições de ensino é a banalização do ato de planejar, para muitos professores se tornou um "ritual" que deve ser comprido semanalmente.

Nessa direção, o preparar as aulas é uma das tarefas que merece cautela. A função do plano é guiar, algo redigido a ser usado como ferramenta. $O$ professor tem que pensar seus dias letivos, incumbir propostas regadas de 
compromisso e significados, antes de ser uma resposta ao grupo que supervisiona.

Para Castro, Tucunduva e Arns (2008, p. 55),

Infelizmente, apesar do planejamento da ação educativa ser de suma importância, existem professores que são negligentes na sua prática educativa, improvisando suas atividades. Em consequência, não conseguem alcançar os objetivos quanto à formação do cidadão.

Os autores nos convidam a refletir sobre a falta de planejamento e sua interferência no meio educacional. O improvisar exclui o sentido e faz desconectar a ideia de formação do cidadão. Esquematizar o trabalho, pensar como agir, terá forte influência quando o papel do professor está além, como já citado anteriormente. O que acontece quando não se tem uma organização? Vamos imaginar uma aula onde o docente não se organizou com antecedência, tem que criar estratégias naquele momento. Essa prática dá brechas para uma possível aula tumultuada, porquanto os alunos podem ficar dispersos, e o tempo da aula é desperdiçado, o que poderá comprometer o rendimento do ensino-aprendizagem. Aula bem ministrada é aula bem planejada, por isso o plano é sobremaneira importante.

Para Zabala (1998, p. 17),

[...] desde uma perspectiva dinâmica e desde o ponto de vista dos professores, essa prática deve ser entendida como reflexiva e não pode se reduzir ao momento em que se produzem os processos educacionais na aula. A intervenção pedagógica tem um antes e um depois que constituem as peças substanciais em toda prática educacional. O planejamento e a avaliação dos processos educacionais são uma parte inseparável da atuação docente, já que o que acontece nas aulas, a própria intervenção pedagógica nunca pode ser entendida sem uma análise que leve em conta as intenções, as previsões, as expectativas e a avaliação dos resultados.

Para o autor, em uma perspectiva dinâmica, o professor compreenderá a prática como reflexiva. Concordamos com esse pensamento, porque, realmente, os docentes devem ter um olhar reflexivo para sua prática e não se limitar a reproduzir os processos educacionais na aula. Tanto o planejamento quanto a avaliação são elementos indissociáveis, o planejamento representa o antes, e a avaliação, o depois, ou seja, planeja, aplica e avalia. 
O docente não deve esquecer que o planejamento faz parte de suas atribuições. É necessário seguir uma linha de raciocínio que direcione o exercício da prática e a coerência das ações pedagógicas a serem desenvolvidas cotidianamente por esse profissional no âmbito escolar. A avaliação dessas atividades se apresenta como subsídios para que o docente possa compreender quais foram os resultados obtidos, as dificuldades encontradas e, só então realizar as demais intervenções.

O docente, nos dias atuais, é convidado a experimentar novas metodologias e a se desprender das que foram herdadas da educação tida como tradicional. Portanto, espera-se que seja ousado e crie, possivelmente, novos métodos de ensino. A reflexão adentra como forte aliada. É preciso permitir analisar a ação educativa, sobretudo as falhas, para que novos direcionamentos sejam indicados.

Reportamo-nos a Zabala (1998, p. 13) quando diz:

Provavelmente a melhoria de nossa atividade profissional, como todas as demais, passa pela análise do que fazemos, de nossa prática e do contraste com outras práticas. Mas certamente a comparação com outros colegas não será suficiente. Assim, pois, frente a duas ou três posições antagônicas, ou simplesmente diferentes, necessitamos de critérios que nos permitem realizar uma avaliação racional e fundamentada.

Nessa direção, analisar o que se faz é uma tarefa importante para qualquer profissional. Para melhorar a prática, é necessário fazer essa reflexão. Avaliar o próprio método é muito importante, assim como observar as práticas de outros colegas. Esse é um recurso do qual se tira aprendizado e que, embora não seja suficiente, contribui. O docente tem que buscar suportes em teóricos para interpretar o que acontece em sala de aula, para que possa fazer uma avaliação racional. Na concepção de Zabala (1998, p. 16),

Os processos educativos são suficientemente complexos para que não seja fácil reconhecer todos os fatores que os definem. A estrutura da prática obedece a múltiplos determinantes, tem sua justificação em parâmetros institucionais, organizativos, tradições metodológicas, possibilidades reais dos professores, dos meios e condições físicas existentes, etc. Mas a prática é algo fluido, fugidio, difícil de limitar com coordenadas simples e, além do mais, complexa, já que nela se expressam múltiplos fatores, ideias, valores, hábitos pedagógicos, etc. 
Essa reflexão nos leva a entender que os processos educativos são abstrusos e que é difícil compreender os fatores que os definem. Existe uma estrutura que elabora determinantes, dos quais a prática não deve ser apartada. Ela se reflete como rígida e resistente às coordenadas simples.

Por isso, a educação é influenciada pelas necessidades que vão surgindo a partir da atuação do docente em sala de aula. Em tempos tão complexos e globalizados não se concebe mais que o professor se limite e se satisfaça com o conhecimento adquirido ao longo de sua formação inicial. Como principal balizador do meio educacional, o professor precisa estar em constante atualização para realizar com maestria a ação de educar.

As leis e os documentos que regem a educação enfatizam o papel da escola na vida do aluno. Nesse sentido, a formação do sujeito deve ser integral, com uma educação que o contemple em todos os aspectos, como, por exemplo: valorizar o trabalho, a cidadania, a ética e a formação cultural. Esses paradigmas justificam a grande responsabilidade da escola na vida do indivíduo. Com o peso de toda essa carga, serão necessários profissionais cada vez mais capacitados para atuarem nesse campo.

\section{Procedimentos metodológicos}

Este trabalho, fruto de uma pesquisa de conclusão de curso, teve por objetivo entender como a organização do planejamento contribui para que a ação educativa se materialize, a partir da percepção de docentes e da equipe pedagógica de escolas localizadas na cidade de Arara - PB. Segundo dados do IBGE (2016), a população estimada, em 2016, foi de 13.448 (treze mil, quatrocentos e quarenta e oito) habitantes em uma área territorial de $99 \mathrm{Km}^{2}$. De acordo com os dados da Secretaria de Educação do Município, o quadro de professores da Educação Infantil e dos Anos Iniciais do ano de 2016 correspondia a quarenta e dois professores, que lecionavam na zona urbana do referido município. O número de matrículas nas cinco escolas pesquisadas totalizou mil e noventa e quatro alunos.

Os participantes da pesquisa foram trinta e cinco docentes e quatro profissionais da equipe pedagógica. Quanto aos educadores, sete são da EMEIF Joaquim Alves da Silva; sete, da EMEIF Maria do Carmo Alves de Morais; onze, da EMEIF Maria do Carmo Castro; cinco, da EMEIF Maria José de Albuquerque; e cinco, da Creche Municipal Padre Lambert de Groot.

Todos os participantes são do sexo feminino, com a seguinte formação: 22 educadoras são formadas em Pedagogia. Dessas, 12 têm Curso de Especialização em alguma área - uma, em Biologia e Marketing; três, com licenciatura 
plena em História; quatro são graduandas em Pedagogia; uma tem Magistério; e quatro não responderam a essa questão. Das turmas em que ensinam, 12 atuam na Educação Infantil e 23, nos anos iniciais do Ensino Fundamental. Das 35 docentes, 14 trabalham em outro turno.

A investigação também contou com a participação de quatro coordenadoras pedagógicas das escolas pesquisadas. Todas têm formação acadêmica apropriada, inclusive em nível de pós-graduação, o que é muito importante para a função que exercem, e demonstraram que têm condições de auxiliar os educadores.

A pesquisa foi do tipo exploratória, com abordagem quanti-qualitativa, a fim de tecer uma explicação geral sobre nosso objeto de estudo. Os dados foram coletados por meio de dois questionários com o intuito de conciliar com a disponibilidade de tempo dos participantes: um, composto de 16 questões fechadas, foi destinado aos professores e sistematizado em blocos temáticos, obedecendo a ordem cronológica; e o outro, com oito perguntas abertas e ordenadas para serem respondidas pela equipe pedagógica. Esses instrumentos foram importantes tanto para a coleta quanto para a interpretação dos dados, porque, por meio deles, tivemos uma visão, senão total, mas bem aproximada da realidade que estávamos investigando.

\section{Resultados e discussões}

Apresentaremos, a seguir, a análise dos dados colhidos por meio do questionário aplicado para as professoras, para verificar como esses sujeitos vivenciam a ação de planejar.

A pesquisadora se interessou por saber quais as concepções que os docentes têm sobre o planejamento. Das participantes, $44 \%$ referiram que é um instrumento orientador de todo o processo educativo; e $2 \%$ o consideraram como algo que só funciona na teoria.

Vasconcellos (2002, p. 43) enfatiza que

Planejar é elaborar o plano de intervenção da realidade, aliado à exigência de intencionalidade de colocação em ação. A elaboração do plano, obviamente, não é ainda a ação; é um processo mental, de reflexão, de decisão; por sua vez, não uma reflexão qualquer, mas "grávida" de intervenção na realidade.

Nessa perspectiva, planejar é uma ação que leva à reflexão, porque, quando se apropria de decisões, o professor prevê algo que poderá se tornar real. Significa se preparar para efetivar uma atividade futura, com a pretensão de alcançar um objetivo. O planejamento auxilia a orientar, a organizar e possibilita ao professor ter uma visualização 
antecipada do que pretende que ocorra. Considerando o número de respostas, a maioria caminha em uma direção certa, mas ainda há vestígios de descrença no planejamento, apesar de ser uma parcela pequena, mas é essa a responsável por nos fazer refletir por que não temos unanimidade nas respostas, quais motivos impedem o planejamento de sair do papel.

Vasconcellos (2002, p. 13) pontua algumas narrativas de professores que se assemelham aos dados encontrados na pesquisa. Ele afirma existirem professores que dizem: "na hora de planejar, tudo bem, mas depois... No papel, o planejamento é bonito, mas, na prática, fica difícil. Na prática, é outra. Planejamento bem elaborado que só permanece no papel [...]". Esse posicionamento se aproxima do encontrado nas respostas dos $2 \%$ dos pesquisados que afirmam justamente o que o autor traz. Há, ainda, os profissionais que não acreditam no planejamento. Fazem seus planos, consideram roteiros esteticamente bonitos, mas encontram dificuldades de pôr em prática seus registros. Essa falta de entusiasmo de não encontrar sentido no que se faz compromete o plano, e planejar acaba sendo perda de tempo.

Para Castro, Tucunduva e Arns (2008, p. 56),

Os professores precisam quebrar o paradigma de que o planejamento é um ato simplesmente técnico e passar a se questionarem sobre o tipo de cidadão que pretendem formar, analisando a sociedade na qual ele está inserido, bem como suas necessidades para se tornar atuante nesta sociedade.

Nesta direção, o planejamento precisa ser realizado de maneira consciente, o registrar não é suficiente, deve haver sentido. Deve-se revestir o ato de planejar de significados, uma vez que esse profissional está bem próximo da formação de sujeitos.

Questionamos os participantes da pesquisa se o planejamento influencia as ações pedagógicas. Os resultados revelaram que o trabalho do professor sofre influência do planejamento, já que a maioria (97\%) dos participantes da pesquisa respondeu sim. Os outros $3 \%$ omitiram a resposta.

Para Cervi (2008, p. 69), "planejar é criar soluções, solucionar impasses e projetar propósitos", é tentar se prevenir para os imprevistos, é traçar metas. É impossível dizer que o planejamento não influencia o desenvolvimento das ações do professor, já que ele é o guia e o que dá sentido ao trabalho pedagógico, portanto, é a essência da ação.

Na terceira questão do bloco, perguntamos às entrevistadas de quem é a tarefa de planejar, se só o professor iniciante é quem deve projetar suas ações e se os com um 
tempo de experiência já acumulado estão deixando de fazê-lo. Unanimemente (100\%), as docentes responderam que não. Isso implica dizer que têm consciência de que planejar é uma atividade de todos os docentes, mesmo os que têm um período maior de atuação.

Refletindo sobre essa questão da experiência, podemos dizer que ela não é dispensada, porém não é suficiente para o profissional desenvolver um bom trabalho. Estamos diariamente expostos a mudanças, razão por que o professor tem que estar em sintonia e se moldando de acordo com as necessidades que vão surgindo. E como os alunos não são homogêneos, a repetição de métodos pode não ser favorável ao desempenho do trabalho do professor. Vasconcellos (2002, p. 35) afirma que

Vivemos, hoje, em um mundo de fragmentação, de correria, em que o sujeito educando tem uma série de outras coisas para fazer, uma série de outros estímulos. Se queremos efetivamente atingi-lo, temos que aproveitar da melhor forma o espaço-tempo de sala de aula. Um bom planejamento certamente tem repercussão na disciplina, uma vez que as necessidades dos alunos estão sendo levadas em conta e o professor tem maior convicção daquilo que está propondo.

Como podemos observar, esse recorte de texto do autor citado é uma escrita de quase duas décadas. No entanto, Vasconcellos já apontava pistas e projeções sobre os dias atuais. Suas interpretações são pertinentes e ainda conciliáveis com o que ocorre em pleno século XXI. Se observarmos melhor, temos a comprovação de suas ideias. Os alunos estão, sim, expostos a situações bem mais estimulantes, o que implicitamente indica à escola que ela necessita de uma prática pedagógica inovadora.

Quando fazemos uso do termo inovação, podemos até relacionar as novas tecnologias, que avançam e tomam conta de todas as áreas da ação humana. Estamos cercados de atrativos, que chamam mais atenção dos alunos do que a escola. O que o professor pode fazer neste caso? Em que contexto podemos relacionar os novos estímulos com o seu trabalho? Para responder a essas questões começaremos enfatizando que o professor é convidado a aprender outros caminhos de como lidar com esses novos paradigmas, de como aproveitar essa inovação tecnológica dentro da sala de aula. Isso se dará através de novos estudos, da capacidade de ser ousado, de fazer testes, de realizar um bom planejamento, de ter convicção do que ensina, e tentar se aproximar da realidade social dos seus alunos.

Destaca-se que essa inovação, porém, não se refere unicamente às tecnológicas. Estas são necessárias, mas é 
imprescindível compreender a realidade dos sujeitos que estão na escola, para auxiliar na sua transformação, pois para Orso (2015),

Seria absurdo compreender a realidade, a sociedade e o mundo em que se está inserido e não fazer nada para transformá-los. Ou seja, não resta outro caminho senão empenhar-se em compreender cada vez melhor o homem, a sociedade, o mundo e a educação e fazer desta um instrumento de conhecimento, aprendizagem, ação e transformação (ORSO, 2015, p. 269).

A questão seguinte remeteu à elaboração do plano anual e perguntamos aos sujeitos da pesquisa se fazem esse plano para sistematizar o trabalho ao longo desse período de tempo. O resultado demonstrou que a equipe pedagógica participa diretamente dessa tarefa, uma vez que a maioria das professoras entende o plano como construção desse grupo que depois é repassado para os educadores. Assim, $66 \%$ das pedagogas assinalaram a opção que corresponde a essa resposta.

Luckesi (2005, p. 113) nos diz que o planejamento de ensino deve se configurar

[...] na previsão inteligente e bem articulada de todas as etapas do trabalho escolar que envolvem as atividades docentes e discentes, de modo que se torne o ensino seguro, econômico eficiente; é a previsão das situações específicas do professor com a classe; é o processo de tomadas de decisões bem informadas das atividades do professor e do aluno, na situação ensino aprendizagem, possibilitando melhores resultados e, em consequência, maior produtividade.

As respostas das professoras não condizem com a afirmação de Luckesi, porque deixam explícito que não estão cumprindo com uma de suas obrigações, previstas no artigo 13 da Lei de Diretrizes e Bases - Lei 9394/96, em cujo inciso II encontramos: "É função do docente elaborar e cumprir plano de trabalho, segundo a proposta pedagógica do estabelecimento de ensino". Além da questão legal, causa estranheza esta ação, que é restrita, exclusivamente, ao docente, ser exercida pela equipe pedagógica. Como pensar a ação docente sem a participação do docente? Este planejamento, então, esvazia-se de sentido.

Quando o planejamento é externo - nesse caso, referimo-nos à equipe pedagógica - é evidente que não vai ser específico para cada turma, tendo em vista uma demanda grande de salas para atender. Ele vai ser elaborado de 
maneira geral, e o professor só irá se preocupar em adaptar, e isso poderá ser preocupante, porque esse plano pode não se aproximar da realidade de determinada turma e, consequentemente, dos alunos. Como vimos, o plano de ensino especifica a concepção de educação, de homem e de sociedade de determinados sujeitos dentro de determinados contextos. Assim, como poderá a equipe pedagógica projetar os fins a serem atingidos sem o conhecimento da sala de aula a que só o docente tem acesso?

Destaca-se, ainda, que a prática da elaboração do planejamento de ensino pela equipe pedagógica encontrada neste município, reflete a realidade de muitos outros e demonstra claramente a percepção que temos do distanciamento dos docentes das metas estabelecidas para cada etapa da educação. Pois, se o educador apenas segue um roteiro pensado por outros, com previsões distantes da realidade com o intuito apenas de cumprir orientações nacionais, como alcançar estes objetivos e metas? Impossível! É preciso que a ação de planejar o ensino seja realizada pelos docentes e com a colaboração restrita da equipe pedagógica.

No que diz respeito à elaboração do plano anual e sua consulta no cotidiano, 63\% afirmaram que o consultam para elaborar seus planos de aula; $20 \%$ omitiram a resposta; e 17\% disseram que os utilizam frequentemente.

Retomando a questão anterior, vimos que o planejamento anual é elaborado pela equipe pedagógica. Isso nos possibilita considerar que, embora seja uma construção externa, os professores afirmam que ele é útil no planejamento de suas aulas.

Segundo Libâneo (2013, p. 257),

O plano de ensino é um roteiro organizado das unidades didáticas para um ano ou semestre. É denominado também como plano de curso ou plano de unidades didáticas e contém os seguintes componentes: justificativa da disciplina em relação aos objetivos da escola; objetivos gerais; objetivos específicos, conteúdo (com a divisão de cada unidade); tempo provável e desenvolvimento metodológico (atividades do professor e dos alunos).

Neste sentido, o plano de ensino envolve a justificativa do trabalho proposto, a organização dos objetivos, as metodologias a serem seguidas e os conteúdos das disciplinas a serem trabalhados. É um plano amplo, que engloba a matriz curricular, visando à direção de atividades sistematizadas a serem ministradas pelos docentes em um tempo razoável. Trata-se de uma referência para facilitar a construção do plano de aula diário. Por isso, mais uma vez, ressalta-se a importância de o plano de ensino ser elaborado 
pelos docentes, para não tornar o plano de aula esvaziado e apenas um roteiro que deverá ser seguido.

Vasconcellos (2002), baseando-se em depoimentos de professores, afirma que nas escolas existem planos que são entregues, mas engavetados e não são consultados. O autor acrescenta que alguns docentes consideram o planejamento como uma estruturação inútil e mais um registro em papéis que permanecerão no arquivo, portanto, não o consultam e, muito menos, levam-no a sério.

Para verificar se essa ideia condiz com a realidade dos colaboradores da pesquisa, elaboramos as questões 5 e 6 , com o intuito de saber se os planos são elaborados, mas ficam engavetados ou se são úteis para o professor. De acordo com os resultados, $83 \%$ dos docentes que responderam a essa questão afirmaram que o plano não é engavetado. Isso significa dizer que é útil, apesar de ser uma construção da equipe de coordenação, sendo citado como auxílio para a organização das aulas. Esse plano, por sua vez, confirma a ideia de suporte para a elaboração do plano de aula.

Os sujeitos da pesquisa afirmaram não arquivar o plano de ensino, usam-no como fonte de apoio para planejar suas aulas. Desta maneira, temos um plano não elaborado pelo próprio professor, feito por outras instâncias, mas que não é desconsiderado.

Libâneo (2013, p. 267) entende que

O plano de aula é um detalhamento do plano de ensino. As unidades e subunidades (tópicos) que foram previstas em linhas gerais são agora especificadas e sistematizadas para a situação real. A preparação de aulas é uma tarefa indispensável e, assim como o plano de ensino, deve resultar num documento escrito que servirá não só para orientar as ações do professor como também para possibilitar constantes revisões e aprimoramentos de ano.

O autor nos leva a uma reflexão relevante sobre a utilidade do plano de ensino, pois, a partir dele, o professor pode extrair, de maneira mais específica, o que foi sugerido na proposta de trabalho para o ano letivo, razão por que a elaboração dos planos diários deve ter como base o plano anual. O plano de aula é uma declaração por escrito, de autoria do próprio professor, em que descreve as atividades pedagógicas a serem realizadas.

Na sequência solicitamos que as docentes marcassem as opções que expressavam a exigência do planejamento feita pela escola e os resultados foram: $35 \%$ das entrevistadas apontaram o planejamento como ferramenta do professor e, por meio dele, há o acompanhamento de seu trabalho, é algo para auxiliar suas atividades, conquistas e dificuldades; $24 \%$ conceberam o planejamento como 
oportunidade de socializar ideias com os colegas; $21 \%$ o definiram como forma de evitar a improvisação e a rotina; $19 \%$ fizeram inferência ao planejamento como instrumento mediador da ação pedagógica; e 1\% se referiu ao planejamento como fazer burocrático.

Sob o ponto de vista de Vasconcellos (2002, p. 34),

O professor é o coordenador do processo educativo de ensino-aprendizagem. Deve assumir seu papel de agente histórico de transformação da realidade escolar, articulando à realidade social mais ampla. Neste contexto, o plano deve ser, antes de mais nada, um instrumento de trabalho para o próprio professor (e não para o coordenador, a secretária da escola, a supervisão), correspondendo ao seu projeto de intervenção na realidade.

Mesmo referindo-se a 2002, essa ênfase ao plano que dê suporte, principalmente, ao professor, continua nos dias atuais. O compromisso deve ser, sobretudo, com ele mesmo, pois se trata de uma ferramenta de uso exclusivo. Se no papel só há um esquema montado para provar que se planeja, essa prática será vazia de sentido.

A pesquisa também se preocupou em saber com que frequência os professores planejam suas aulas. Os resultados demonstraram que eles o fazem semanalmente. Entre as opções apresentadas, destacou-se o percentual de $74 \%$, que representou a maior frequência, ou seja, preparam as aulas para a semana inteira; os outros $26 \%$ planejam suas aulas diariamente.

Libâneo (2013, p. 267) enuncia que "[...] é na aula que organizamos ou criamos situações docentes, as condições e os meios necessários para que os alunos assimilem ativamente conhecimentos”. Essa é uma esquematização que visa auxiliar o processo de ensino e aprendizagem.

Também questionamos as entrevistadas sobre o tempo que o professor utiliza para planejar as aulas e $48 \%$ citaram o fim de semana; $26 \%$ disseram que levam de uma a duas horas para planejar as aulas; $20 \%$, de três a quatro horas; e 6\%, que o fazem em outro momento.

De acordo com a Lei de Diretrizes e Bases, $n^{0}$ 9394/96 - LDB (BRASIL, 2005),

O professor tem como incumbência não só ministrar os dias letivos e horas aulas estabelecidas, mas também participar de forma integral dos períodos dedicados ao planejamento, além de participar devem colaborar na elaboração da proposta pedagógica do estabelecimento de ensino ao qual ele pertença. 
Convém enfatizar que, tanto na rede pública quanto a privada, precisa-se de tempo destinado para o planejamento das aulas. Nas instituições públicas o profissional tem que cumprir esse período, nomeado como horário de departamento, fazendo uso com aproveitamento, e onde pode trocar ideias com outros profissionais e elaborar seu plano. As instituições privadas não ficam distantes, há um tempo que pode ser utilizado em casa na realização desses planos, onde o professor é recompensado financeiramente, em algumas escolas. Esta prática de planejar em casa nos finais de semana, na maioria das vezes, provoca a falta de interação com outros colegas, o que que proporcionaria uma reflexão coletiva.

Procuramos saber, também, quais as fontes de consulta mais utilizadas para a elaboração do planejamento. Os maiores índices, 42\%, apontaram para o livro didático e $35 \%$ usam a internet. Por outro lado, percebemos que as docentes não dão o valor necessário a uma fonte tão rica como os Parâmetros Curriculares Nacionais, pois poucas os citaram. Apesar de ser mencionado apenas por alguns, os PCNs servem como norteadores, tanto para professores, como para os responsáveis pelo fazer pedagógico. Quanto ao livro didático - a fonte mais citada - concordamos com Vercez e Silvino (2008, p. 85) quando dizem que

O livro não deve ser considerado como única fonte de conhecimento disponível para o educando, mesmo sendo utilizado de forma didática e corretamente em sala de aula, pois o professor deve ter consciência da necessidade de um trabalho diversificado e, para tanto, é preciso buscar, em outras fontes, informações ou conteúdos que venham a complementar e enriquecer o livro didático.

O ideal é que esse recurso seja utilizado moderadamente, já que existem outras fontes que podem ser exploradas e enriquecer o processo de ensino-aprendizagem. $\mathrm{O}$ foco apenas no livro mantém professores limitados, e seu uso abusivo torna a aula enfadonha e desgastante. Esse instrumento pode ser um guia em relação aos conteúdos. É importante que o profissional o tenha como base, mas nada impede que recorra a outras estratégias. Aulas diversificadas atraem a atenção do educando.

Em relação ao uso da internet, está cada vez mais próxima dos professores, como aliada para o preparo de suas aulas, porquanto proporciona um vasto campo de informações e de ideias. É uma janela que se abre para que pesquisem sugestões de aulas e consultem trabalhos de outros profissionais em que possam se basear para compartilhar experiências vivenciadas. Além do mais, a rede faz 
parte da modernidade, e o educador tem que ter acesso, de uma maneira ou de outra, para usá-la como ferramenta que contribua com seu trabalho.

Ao serem indagadas sobre possíveis dificuldades de planejar as aulas, 63\% das entrevistadas disseram que não têm dificuldades de realizar o planejamento, porque isso já faz parte de sua rotina. $18 \%$ referiram que elaboram o plano de aula, mas, quando partem para a prática, a aula não flui como foi planejada; $16 \%$ asseveram que às vezes sentem dificuldades de pensar em suas ações, e 3\% disseram que têm dificuldades de fazê-lo.

Ao prosseguir a investigação, procuramos saber se a equipe pedagógica contribui dando suporte para o professor elaborar os planos de aula. Os dados levantados deixaram evidente que existe uma coordenação ativa, e as ações dos professores recebem a influência dessa categoria. O percentual de $89 \%$ respondeu que a equipe pedagógica lhes dá suporte para elaborar o plano de aula, que há parceria e, inclusive, a disponibilização de material e sugestões para o professor planejar sua aula. 11\% responderam que a equipe dá suporte às vezes sim e outras, não.

A penúltima questão do bloco foi sobre a rotina da aula, se ela segue de acordo com o planejado. Temos o percentual de $66 \%$ das participantes da pesquisa que afirmaram, algumas vezes sim, em outras, não; 20\%, que não, porque sempre acontece algum imprevisto que impede de realizar o esperado; e apenas $14 \%$ disseram que tudo ocorre como planejado. Aqui se confirma o que foi mencionado: a maioria, ao responder que às vezes sim, outras não, apontam indícios de flexibilidade, do planejado sofrer alteração e de não atingirem o que esperam.

Na última questão indagamos quais elementos constituem o plano de aula dos professores. Os resultados indicaram que a maioria (60\%) elabora seus planos considerando os seguintes elementos: objetivos, metodologia, recursos e avaliação; 20\% responderam que descrevem apenas os procedimentos da aula; $14 \%$, os objetivos e a metodologia; e 6\% citaram três dos elementos.

Dando sequência às análises, apresentaremos, de maneira geral, as respostas das coordenadoras coletadas por meio de questões abertas que foi destinado à equipe de coordenação. Oliveira e Guimarães (2013, p. 95) defendem que "o coordenador precisa ter uma formação inicial e continuada para que possa desenvolver com afinco suas atribuições dentro da escola, sendo a principal delas a formação em serviço dos professores”. Esse profissional é uma peça fundamental na articulação do fazer pedagógico, cujas principais atribuições são de planejar e de conduzir as reuniões pedagógicas na escola e acompanhar o planejamento de cada professor e o resultado das aprendizagens dos alunos. 
Quando perguntados sobre as atividades desenvolvidas pela equipe pedagógica, os sujeitos da pesquisa mostraram uma equipe ativa. Suas colocações coincidem com as funções que competem a um coordenador em sua atuação dentro da unidade escolar. Sobre isso, Oliveira e Guimarães (2013, p. 98) nos dizem que

A ação efetiva do coordenador pedagógico, com sua equipe escolar, é de extrema importância para o bom trabalho, para a melhoria do fazer pedagógico da sala de aula. Além disso, o coordenador pedagógico busca integrar todos no processo ensino-aprendizagem, mantendo as relações interpessoais de maneira saudável, valorizando a formação dos seus profissionais, ajudando-os efetivamente na construção dos saberes da sua profissão.

Nesta mesma linha de pensamento, referimos que a principal atribuição do coordenador pedagógico é de ser um formador dos professores. Ele tem a função de atualizar os docentes, com formações, tendo em vista que esses profissionais precisam de parceria, de interlocução e de colaboração da escola. O coordenador precisa ficar próximo dos professores e da sala de aula e manter com eles uma relação de trabalho indissociável. São grupos que devem caminhar juntos, procurando melhores mecanismos para o processo de aprendizagem dos alunos.

As coordenadoras também foram perguntadas sobre a solicitação do planejamento de ensino aos professores. Elas foram unânimes em afirmar que sim. Essa pergunta estava no bloco de questões de ambas as categorias, com o propósito de comparar as respostas. Quanto aos professores, a maioria asseverou que não elabora o plano porque a equipe pedagógica é responsável por essa tarefa; outra parte disse que faz, porque as coordenadoras solicitam. Assim, fica difícil compreender quem é que realmente elabora o plano de ensino, porque as coordenadoras responderam de maneira contrária aos professores, quando afirmam solicitar aos professores que eles mesmos preparem seu plano.

Levantamos outra questão acerca do planejamento, a fim de averiguar se as professoras têm dificuldades de fazê-lo e por quê. Houve predominância em suas respostas, quando citaram a resistência de muitos professores para fazerem o planejamento. A maioria das coordenadoras não considera uma provável dificuldade para planejar, tendo em vista um quadro de docentes qualificados que podem realizar com sucesso essa função. Fica implícita a falta de disposição do professor para traçar um bom planejamento e colocá-lo em prática.

Tivemos também o interesse em saber como os professores são orientados para planejar as aulas. A equipe 
afirmou que eles recebem orientações para isso e para definir seus objetivos e que tentem alcançá-los. Solicitam a realização de sequências didáticas, organizadas e articuladas para facilitar a prática, e orientam o professor a sintonizar o planejamento com o currículo da escola.

Indagamos às coordenadoras como acompanham o trabalho do professor e responderam que o acompanhamento é minucioso e citaram várias estratégias para realizar essa tarefa. A observação foi a mais ressaltada como instrumento, não com o intuito de fiscalizar, mas de saber quais os pontos que carecem de mais atenção e como as aulas estão acontecendo. É importante esse olhar de fora, porquanto a devolutiva ao professor ajuda a encontrar soluções, caso o trabalho docente não esteja caminhando como deveria, e a observar os acertos. Esse feedback serve para impulsionar possíveis reflexões.

A visualização do caderno do aluno também foi citada como recurso que leva a compreender como está sendo o desenrolar das atividades do professor, porque traz indícios dos conteúdos trabalhados, além de ser um meio de analisar a aprendizagem do educando - se tem letra legível ou não, se obedece aos critérios de organização, se o professor está atento às questões de ortografia ou outra dificuldade apresentada pelos alunos. As reuniões pedagógicas são mencionadas como encontros em que os professores têm a oportunidade de compartilhar experiências, de adquiri-las e de se manterem informados sobre o calendário escolar. Por fim, afirmam olhar o registro dos planos de aula dos educadores antes de serem aplicados.

Questionamos, ainda, se o professor se compromete a executar o que foi repassado pela equipe pedagógica e se as ações registradas saem do papel. A análise das respostas nos levou a entender que a maioria dos professores acata as sugestões que são repassadas pela equipe pedagógica e fazem as devidas adaptações à realidade de cada sala de aula. Mais uma vez, aparece a questão da resistência do professor para elaborar a sua proposta de trabalho, talvez até mais dinâmica, que facilite o processo de ensino e de aprendizagem. Os sujeitos ressaltaram que há professores que ignoram o trabalho do coordenador, embora esse seja indissociável. Portanto, a parceria deve existir e o trabalho do professor não deve seguir isoladamente.

Quando perguntados se havia professores que se destacam com aulas diferentes, os sujeitos da pesquisa responderam que existem os que são comprometidos com o ato de ensinar e são dinâmicos em sua proposta de trabalho na sala de aula, com estratégias para estimulá-los a aprender os conteúdos repassados. As entrevistadas também mencionaram os bons rendimentos obtidos com essa metodologia 
e que esses docentes têm uma visão privilegiada do perfil do professor para os dias atuais.

Para finalizar a pesquisa, considerando o que foi discutido acerca do planejamento, solicitamos aos sujeitos que apresentassem uma definição para o termo "planejamento". Todas as respostas remeteram ao planejamento como um instrumento importante para a prática pedagógica, reafirmando o que já estamos discutindo desde o início do trabalho como uma ação consciente, sistemática e organizada, primordial para o professor.

\section{Conclusão}

Ao realizar este estudo, assumimos o desafio de compreender como o planejamento contribui como ferramenta para materializar a ação educativa. Ressaltamos que os objetivos que elencamos foram todos atingidos.

A pesquisa de campo teve excelente representação, porquanto contou com a colaboração de $83 \%$ dos professores que lecionam na educação infantil e nos anos iniciais e $100 \%$ da equipe de coordenadoras pedagógicas que atuam nas escolas públicas do município de Arara-PB. Para ambas as categorias, o planejamento deve ser enfatizado como parte especial de suas funções. A representação que tivemos foi o suficiente para comprovar que o ato de planejar é sobremaneira significativo e contribui para impulsionar o sucesso escolar.

Os dados colhidos com a aplicação do questionário para as professoras revelaram que elas consideram o planejamento essencial para que as ações se concretizem. Notamos que uns professores anteciparam as ações a serem desenvolvidas com mais rigor, e outros, nem tanto, mas todos foram submetidos a elaborar seu planejamento. Os resultados confirmaram que, para haver prática pedagógica, é preciso planejar.

A participação da equipe de coordenadoras foi muito significativa e nos possibilitou ver de outro ângulo o planejamento. O questionário visou investigar se o posicionamento dos professores era condizente com as respostas do coordenador pedagógico, fazendo uma ponte entre as respostas. Assim, considerando o que nos foi apresentado pelas coordenadoras, constatamos que, de fato, o planejamento é uma rotina na prática dos professores. Entretanto, alguns ainda resistem a fazê-lo.

Abrimos um parêntese para falar de uma questão que nos chamou bastante atenção - o planejamento de ensino - pois, nessa questão, houve contradições e tivemos dificuldade de compreendê-la. De um lado, os professores dizem que não elaboram o plano de ensino porque a equipe o repassa pronto; de outro, as coordenadoras afirmam que 
solicitam o plano, porém ele é construído, e as demais respostas afirmam sua utilização.

Vale ressaltar que foi de extrema importância a colaboração dos professores das escolas pesquisadas e da equipe pedagógica, que não se opuseram a participar da pesquisa. Contribuições semelhantes deram os teóricos mencionados no decorrer do desenvolvimento deste trabalho, que foram fundamentais, principalmente, para nossas análises e reflexões.

De modo geral, os dados comprovaram a riqueza e o significado do ato de planejar. Vale insistir que essa prática é muito relevante na educação. Afinal, o planejamento é responsável pela organização e pelo direcionamento de um trabalho de boa qualidade.

\section{Referências}

BRASIL. Lei de Diretrizes e Bases da Educação Nacional. Brasília: Senado Federal, 2005.

CASTRO, Patrícia A. P. P. de; TUCUNDUVA, Cristiane Costa; ARNS, Elaine Mandelli. A importância do planejamento das aulas para a organização do trabalho do professor em sua prática docente. ATHENA. Revista Científica de Educação, v. 10, n. 10, jan./jun. 2008.

CERVI, Rejane de Medeiros. Planejamento e avaliação educacional. 2. ed. rev., atual. e ampl. Curitiba: Ibpex, 2008.

GOMES, Édula Maria Fonseca. A importância do planejamento para o sucesso escolar. Porto Nacional - TO: Universidade Federal de Tocantins-UFT, 2011. Disponível em: <file://C:/Users/Silvia\%20Oliveira/Downloads/ Edula_corrigido_ULTIMA_VERSAAO\%20(1).pdf $>$. Acesso em: 04 maio 2019.

IBGE. Instituto Brasileiro de Geografia e Estatística. Disponível em: <http://ibge.gov.br/cidadesat/xtras/perfil.ph p?lang $=\& \operatorname{codmun}=250090 \&$ search $=$ paraiba\%7Carara $>$. Acesso em: 13 set. 2016.

LIBÂNEO, José Carlos. Didática. 2. ed. São Paulo: Cortez, 2013.

LUCKESI, Cipriano Carlos. Avaliação da aprendizagem escolar: estudos e proposições. 17. ed. São Paulo: Cortez, 2005.

MENEGOLLA, Maximiliano; SANT>ANNA, Ilza Martins. Por que planejar? Como planejar? 7. ed. Petrópolis, RJ: Vozes, 1999. 
OLIVEIRA, Juscilene da Silva; GUIMARÃES, Marcia Campos Moraes. O papel do coordenador pedagógico no cotidiano escolar. Revista Científica do Centro de Ensino Superior Almeida Rodrigues, ano I, 1. ed., jan. 2013.

OLIVEIRA, Manoel Cipriano. Plano de aula: ferramenta pedagógica da prática docente. Pergaminho, Patos de Minas: UNIPAM, v. 2, p. 121-129, nov. 2011.

ORSO, Paulino José. Planejamento escolar em tempos de precarização da educação. Revista HISTEDBR On-line, Campinas, n. 65, p. 265-279, out. 2015.

TAKAHASAI, R. T.; FERNANDES, M. F. P. Plano de aula: conceitos e metodologia. Acta Paul. Enf., São Paulo, v. 17, n. 1, p. 114-8, 2004.

VASCONCELLOS, Celso dos Santos. Planejamento: plano de ensino - Aprendizagem e projeto educativo - elementos metodológicos para elaboração e realização. 10. ed. São Paulo: Libertad, 2002. (Cadernos Pedagógicos da Libertad; v. 1).

VERCEZ, Rosa Maria Aparecida; SILVINO, Eliziane França Moreira. O livro didático e suas implicações na prática do professor nas escolas públicas de Guarajá Mirim. Práxis Educacional, Vitória da Conquista, v. 4, n. 4, p. 83102, jan./jun. 2008.

ZABALA, Antoni. A prática educativa: como ensinar. Tradução: Ernani F. da F. Rosa. Reimpressão 2010. Porto Alegre: Artmed, 1998.

Recebido em: 20-10-2018 Aprovado em: 23-04-2019 Publicado em: 22-05-2020 